\title{
The Formation of Extragraft Bone Bridging after Anterior Cervical Discectomy and Fusion : A Finite Element Analysis
}

\author{
Shin Won Kwon, M.D., ${ }^{1}$ Chi Heon Kim, M.D., Ph.D.,, ${ }^{1,2,3}$ Chun Kee Chung, M.D., Ph.D., ${ }^{1,2,4}$ Tae Hyun Park, M.S., ${ }^{5,6}$ Su Heon Woo, M.S., \\ Sung-Jae Lee, Ph.D., ${ }^{5}$ Seung Heon Yang, M.D. ${ }^{1,2,3}$ \\ Department of Neurosurgery, Seoul National University Hospital, Seoul, Korea \\ Department of Neurosurgery, ${ }^{2}$ Seoul National University College of Medicine, Seoul, Korea \\ Clinical Research Institute, ${ }^{3}$ Seoul National University Hospital, Seoul, Korea \\ Department of Brain and Cognitive Sciences, ${ }^{4}$ Seoul National University College of Natural Sciences, Seoul, Korea \\ Department of Biomedical Engineering, Inje University, Gimhae, Korea \\ $R \& D$ Center, ${ }^{6}$ Medyssey Co., Ltd, Jecheon, Korea
}

Objective : In addition to bone bridging inside a cage or graft (intragraft bone bridging, InGBB), extragraft bone bridging (ExGBB) is commonly observed after anterior cervical discectomy and fusion (ACDF) with a stand-alone cage. However, solid bony fusion without the formation of ExGBB might be a desirable condition. We hypothesized that an insufficient contact area for InGBB might be a causative factor for ExGBB. The objective was to determine the minimal area of InGBB by finite element analysis.

Methods : A validated 3-dimensional, nonlinear ligamentous cervical segment (C3-7) finite element model was used. This study simulated a single-level ACDF at C5-6 with a cylindroid interbody graft. The variables were the properties of the incorporated interbody graft (cancellous bone [Young's modulus of 100 or $300 \mathrm{MPa}$ ] to cortical bone [10000 MPa]) and the contact area between the vertebra and interbody graft (Graft-area, from 10 to $200 \mathrm{~mm}^{2}$ ). Interspinous motion between the flexion and extension models of less than $2 \mathrm{~mm}$ was considered solid fusion.

Results : The minimal Graft-areas for solid fusion were $190 \mathrm{~mm}^{2}, 140 \mathrm{~mm}^{2}$, and $100 \mathrm{~mm}^{2}$ with graft properties of 100, 300, and $10000 \mathrm{MPa}$, respectively. The minimal Graft-areas were generally unobtainable with only the formation of InGBB after the use of a commercial stand-alone cage.

Conclusion : ExGBB may be formed to compensate for insufficient InGBB. Although various factors may be involved, solid fusion with less formation of ExGBB may be achieved with refinements in biomaterials, such as the use of osteoinductive cage materials; changes in cage design, such as increasing the area of polyetheretherketone or the inside cage area for bone grafts; or surgical techniques, such as the use of plate/screw systems.

Key Words : Spinal fusion · Cervical vertebra · Surgery · Grafts · Finite element analysis.

- Received : June 1, 2017 •Revised : July 5, 2017 •Accepted : July 20, 2017

- Address for reprints : Chun Kee Chung, M.D., Ph.D.

Department of Neurosurgery, Seoul National University College of Medicine, 101 Daehak-ro, Jongno-gu, Seoul 03080, Korea Tel : +82-2-2072-2352, Fax : +82-2-744-8459, E-mail : chungc@snu.ac.kr

This is an Open Access article distributed under the terms of the Creative Commons Attribution Non-Commercial License (http://creativecommons.org/licenses/by-nc/4.0) which permits unrestricted non-commercial use, distribution, and reproduction in any medium, provided the original work is properly cited. 


\section{INTRODUCTION}

Anterior cervical fusion is a common surgical procedure for patients with degenerative cervical disease, and a solid bony union is necessary for successful outcomes ${ }^{1,13,18,20,22,23)}$. To achieve a solid bony union, the intervertebral spaces are filled with autologous bone, allogenic bone or bone material ${ }^{4,9,12)}$, and a cage and/or anterior plate/screw system is utilized to provide initial stability ${ }^{13,14)}$. Usually, bone bridging occurs 3-6 months postoperatively and consolidates for $1-2$ years $^{21)}$. To evaluate spinal fusion, interspinous motion in dynamic cervical radiographs and/or bony bridging in computed tomography (CT) scan are assessed ${ }^{1,19,20)}$. However, the presence of bone bridging in CT scans is not sufficient for defining a solid bony union ${ }^{1,22)}$. Extragraft bone bridging (ExGBB) which is defined as any peripheral bone bridging with no lucent lines crossing the peripheral margins of the operated disc space outside the graft or cage ${ }^{22)}$ has been observed in many patients and is frequently observed after the use of a stand-alone cage for anterior cervical discectomy and fusion (ACDF) ${ }^{15}$. Recent studies assessing cervical spinal fusion in revision surgeries have demonstrated that intragraft bone bridging (InGBB), which means any cortical or trabecular (cancellous) bone bridging with no lucent lines within the confines of the graft or cage observed in CT scans, is not sufficient for solid fusion and that ExGBB is required for solid fusion in most patients $^{1,22)}$. However, the location of ExGBB at either the anterior or posterior margin of a cage or graft is unpredictable, and the formation of ExGBB into the spinal canal may not be desirable $^{1,15,21,22)}$. Therefore, we may need to identify a means of achieving solid fusion with no or less formation of ExGBB. We hypothesized that the contact area between InGBB and the vertebra may not be sufficient for solid fusion and that ExGBB forms to compensate for insufficient area of InGBB for solid fusion. The objective of the present study was to determine, using finite element analysis (FEA), the minimal area of contact surface between an interbody graft and vertebra to achieve solid fusion after single-level ACDF.

\section{MATERIALS AND METHODS}

\section{C3-7 cervical spine finite element model}

A previously validated 3-dimensional, nonlinear ligamen- tous cervical segment (C3-7) finite element model was used for the present study (Fig. 1) ${ }^{10)}$. The geometrical data of the current multi-segmental cervical model were reconstructed from CT scans of a 26-year old man with no pathologies. The information of the material properties were selected from the literature (Table 1) ${ }^{5-7,10,16,24,25)}$. The model included vertebral bodies, bony posterior elements, intervertebral discs, and six major groups of ligaments : the anterior longitudinal ligament (ALL), the posterior longitudinal ligament (PLL), the ligament flavum, the facet capsular ligament, the interspinous ligament and the supraspinous ligament ${ }^{10)}$. The vertebral body consists of an outer shell of high-strength cortical bone reinforced internally by cancellous bone with a thickness of $0.5 \mathrm{~mm}$ (on average $)^{10)}$. The bony posterior element includes the pedicle, lamina, transverse processes, spinous processes and articular

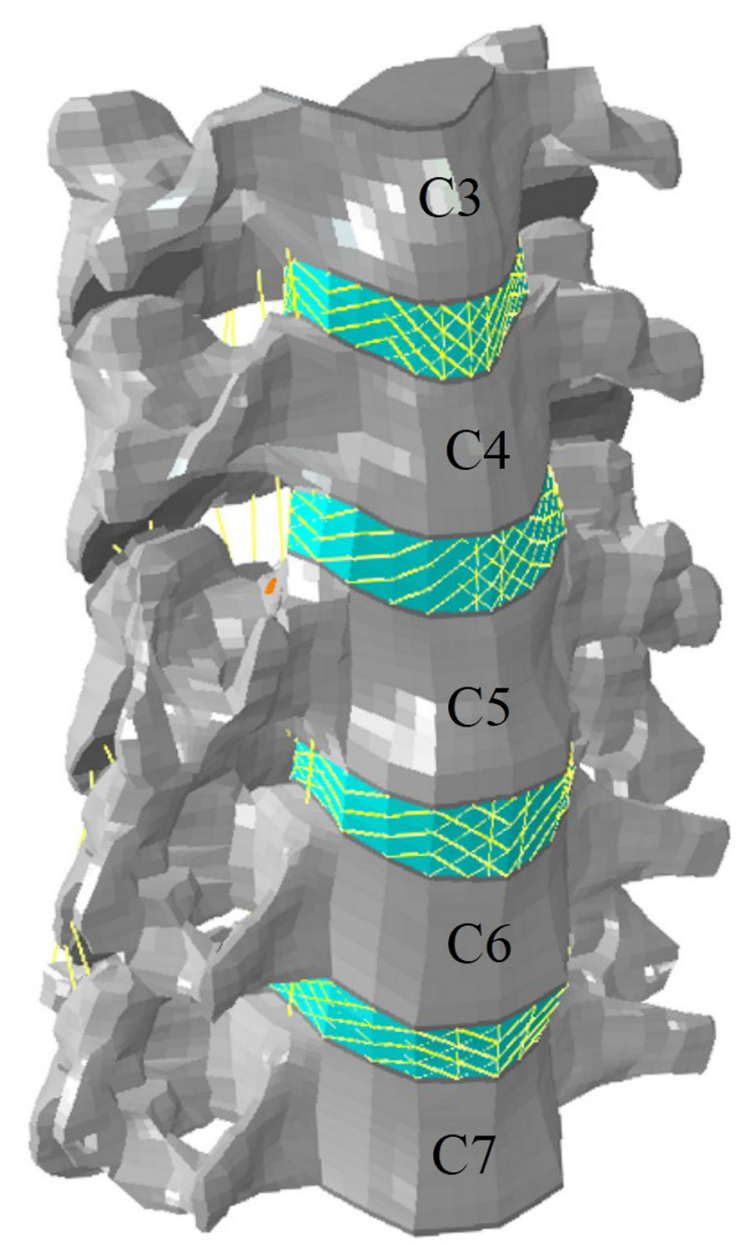

Fig. 1. Finite element model. The geometrical data for the current multisegmental cervical model (C3-7) were reconstructed from computed tomography scans of a 26 -year-old man with no pathologies. 
Extragraft Bone Bridging | Kwon SW, et al.

Table 1. Material properties

\begin{tabular}{|c|c|c|c|c|c|c|c|}
\hline & & $\begin{array}{l}\text { Material } \\
\text { behavior }\end{array}$ & Material type & $\begin{array}{l}\text { Young's } \\
\text { modulus } \\
\text { (MPa) }\end{array}$ & $\begin{array}{l}\text { Poisson's } \\
\text { ratio (n) }\end{array}$ & $\begin{array}{c}\text { Cross- } \\
\text { sectional area } \\
\left(\mathrm{mm}^{2}\right)\end{array}$ & References \\
\hline \multirow{4}{*}{$\begin{array}{l}\text { Vertebral } \\
\text { body }\end{array}$} & Cancellous bone & Linear-elastic & Isotropic & 100 & 0.3 & & Galbusera et al..$^{6}$ \\
\hline & Cortical bone & Linear-elastic & Isotropic & 12000 & 0.3 & & Galbusera et al. ${ }^{6}$ \\
\hline & Posterior element & Linear-elastic & Isotropic & 3500 & 0.29 & & Zhang et al. ${ }^{25)}$ \\
\hline & End plate & Linear-elastic & Isotropic & 500 & 0.4 & & $\mathrm{Ha}^{7)}$ \\
\hline \multirow[t]{3}{*}{$\begin{array}{l}\text { Intervertebral } \\
\text { disc }\end{array}$} & Nucleus pulposus & Linear-elastic & $\begin{array}{l}\text { Isotropic } \\
\text { (incompressible) }\end{array}$ & 1.0 & 0.499 & & Galbusera et al. $\left.{ }^{6}\right)$ \\
\hline & Annulus grounds & Linear-elastic & Isotropic & 4.2 & 0.45 & & $\mathrm{Ha}^{7)}$ \\
\hline & Annulus fibers & Linear-elastic & Isotropic & 500 & & 0.1 & Galbusera et al. .) $^{\circ}$ \\
\hline \multirow[t]{3}{*}{ Bone graft } & Cancellous bone 1 & Linear-elastic & Isotropic & 100 & 0.3 & & Galbusera et al. ${ }^{6)}$ \\
\hline & Cancellous bone 2 & Linear-elastic & Isotropic & 300 & 0.3 & & Mackiewicz et al. ${ }^{16)}$ \\
\hline & Cortical bone & Linear-elastic & Isotropic & 10000 & 0.3 & & Mackiewicz et al. ${ }^{16)}$ \\
\hline \multirow[t]{5}{*}{ Ligament } & $\begin{array}{l}\text { Anterior longitudinal } \\
\text { ligament }\end{array}$ & Hyper-elastic & Tension-only & Non-linear & & 11.1 & $\begin{array}{l}\text { Galbusera et al. }{ }^{6} \text {; } \\
\text { Yoganandan et al. }{ }^{24)}\end{array}$ \\
\hline & $\begin{array}{l}\text { Posterior longitudinal } \\
\text { ligament }\end{array}$ & Hyper-elastic & Tension-only & Non-linear & & 11.3 & $\begin{array}{l}\text { Galbusera et al. }{ }^{6} \text {; } \\
\text { Yoganandan et al. }{ }^{24)}\end{array}$ \\
\hline & Ligament flavum & Hyper-elastic & Tension-only & Non-linear & & 46.0 & $\begin{array}{l}\text { Galbusera et al. }{ }^{6)} \text {; } \\
\text { Yoganandan et al. }{ }^{24)}\end{array}$ \\
\hline & Interspinous ligament & Hyper-elastic & Tension-only & Non-linear & & 13.0 & $\begin{array}{l}\text { Galbusera et al. }{ }^{6)} ; \\
\text { Yoganandan et al. }{ }^{24)}\end{array}$ \\
\hline & Capsular ligament & Hyper-elastic & Tension-only & Non-linear & & 42.2 & $\begin{array}{l}\text { Galbusera et al. }{ }^{6)} ; \\
\text { Yoganandan et al. }\end{array}$ \\
\hline
\end{tabular}

processes (facet joint) ${ }^{10)}$. The eight node brick elements are used for body structures whose material properties were assumed to be homogeneous and isotropic ${ }^{3,7,10,25)}$. The origins and insertions of the six ligaments were obtained from a morphological study ${ }^{10)}$. The spinal ligaments adopt the nonlinear load displacement property for the physiological nonlinear behavior of the ligaments ${ }^{6,10)}$. The intervertebral disc is modeled as a fiber-reinforced structure surrounding the incompressible nucleus pulposus ${ }^{10}$. The reinforcement structure (annulus fibers) is modeled by truss elements with the modified tension-only properties with an orientation of approximately $25^{03,10)}$. The facet joint is oriented at $45^{\circ}$ from the horizontal plane, where the initial surface gaps between each facet region are assumed to be $0.5 \mathrm{~mm}$ based on CT imaging ${ }^{10}$. The interaction of the facet joints facilitates increased contact force with the narrowing of the initial gap distance between the upper and lower facet surfaces ${ }^{3,10,25}$. The segmental angular measures used to create the lordotic curve for the model were as follows : C3-4, 4.35 ; C4-5, 1.87 ${ }^{\circ}$ and C5-6, 3.94 ${ }^{\circ 8,10)}$. The general-purpose FEA package ABAQUS (Habbitt; Karlsson and Sorensen, Inc., Providence, RI, USA) was used in this study. This study was approved by the institutional review board (Nos. 1512-126-729 and 1607-003-771).

\section{Analysis}

The present study simulated a single-level ACDF at C5-6 without the use of a plate/screw system because C5-6 is the most common surgical level ${ }^{14}$. The interbody graft was anteriorly implanted after removal of the ALL, the intervertebral disc and the PLL ${ }^{16}$. We assumed that ideal fusion is the complete incorporation of the interbody graft to the cranial and caudal vertebra. In the model, the interbody graft was completely united with the cranial and caudal vertebrae (Fig. 1). The height of the interbody graft was identical to the original disc height (anterior, $7.36 \mathrm{~mm}$; posterior, $4.46 \mathrm{~mm}$ ). The property of the interbody graft varies when bone fusion is achieved because the incorporated interbody graft undergoes remodel- 


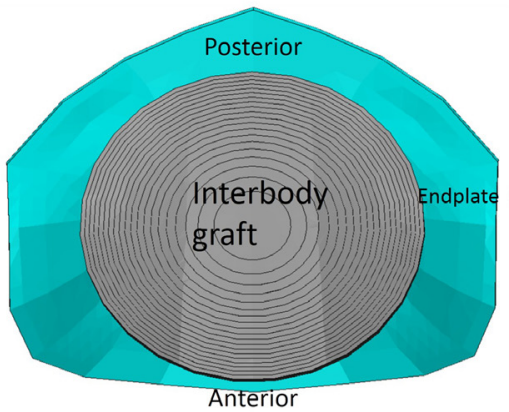

Axial view

Depth : Width $=12: 14$

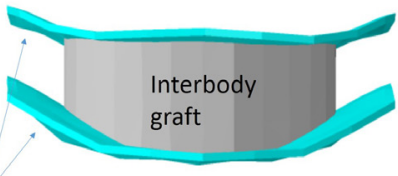

Anterior-Posterior view

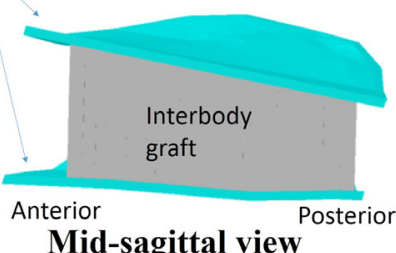

Mid-sagittal view ing $^{21)}$. Therefore, the FEA variables were the property of the incorporated interbody graft and the area of contact surface between the vertebra and interbody graft (Graft-area). The property of the interbody graft ranged from cancellous bone (Young's modulus 100 or $300 \mathrm{MPa}$ ) to cortical bone (10000 $\mathrm{MPa})^{10,16)}$. The morphology of the interbody graft was simplified as a cylindroid shape, and the Graft-area was increased from 10 to $200 \mathrm{~mm}^{2}$ in intervals of $10 \mathrm{~mm}^{2}$ (Fig. 2). A compressive follower load of $73.6 \mathrm{~N}$ and a pure moment of $1.0 \mathrm{Nm}$ were applied on both the flexion and extension motions ${ }^{10,16,17)}$, and the interspinous distance was measured between the spinous processes of C5 and C6 in flexion and extension finite element models (interspinous motion) (Fig. 3). This method is identical to that used in plain radiographs ${ }^{23)}$. The measurements were repeated in three different interbody grafts with properties of $100 \mathrm{MPa}, 300 \mathrm{MPa}$, and $10000 \mathrm{MPa}$. Similar to the criteria used with plain radiographs, interspinous motion between flexion and extension models of less than $2 \mathrm{~mm}$ was considered solid fusion ${ }^{11}$. To compare the present results with existing commercial interbody cages, the areas of three different polyetheretherketone (PEEK) cages were analyzed ${ }^{14)}$. The areas inside the cages where bone graft filled in (Inside), the PEEK contact surface (PEEK) and the total contact surface (Inside+PEEK) of the MC+ ${ }^{\circledR}$ cage (LDR Medical, Troyes, France), Solis ${ }^{\mathrm{TM}}$ cage (Stryker, Kalamazoo, MI, USA), and C7 cage (Medyssey, Jecheon, Korea) are presented in Table 2.

\section{RESULTS}

The interspinous motions according to the property and Graft-area of the interbody graft are described in Table 3 and
Fig. 2. Interbody graft. The morphology of an interbody graft is simplified as a cylindroid shape. In the axial view, the depth/ width ratio is $12 / 14$, and the area of contact surface increases from 10 to $200 \mathrm{~mm}$ in increments of $10 \mathrm{~mm}^{2}$, starting from the center. The area of the endplate in the vertebra is $227.42 \mathrm{~mm}^{2}$. In the anterior-posterior and mid-sagittal views, the interbody graft is completely united with the cranial and caudal vertebrae. In the mid-sagittal view, the height of the interbody graft is identical to the original disc height (anterior, $7.36 \mathrm{~mm}$; posterior, $4.46 \mathrm{~mm})$.

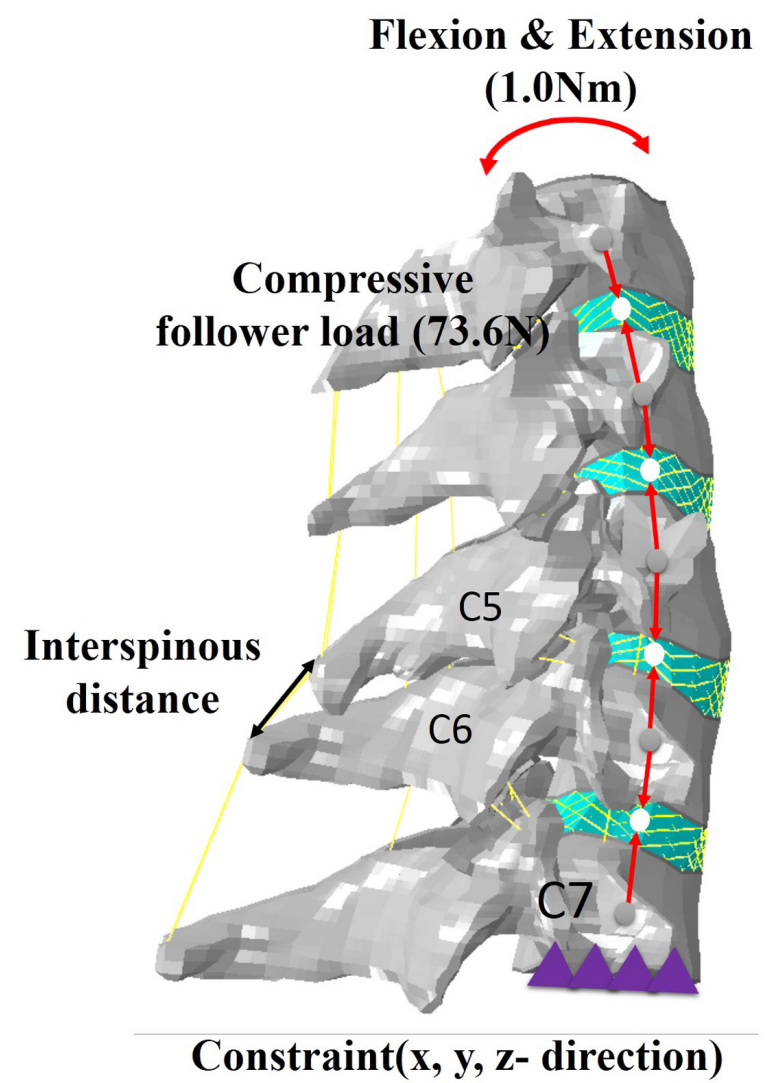

Fig. 3. Measurement of interspinous motion between the flexion and extension finite element models. A compressive follower load of $73.6 \mathrm{~N}$ and a pure moment of $1.0 \mathrm{Nm}$ were applied on both the flexion and extension motions, and the interspinous distance was measured between spinous processes $\mathrm{C} 5-6$ in flexion and extension models after implantation of an interbody graft. The inferior surface of $\mathrm{C} 7$ was rigidly fixed in all directions.

Fig. 4. The measurements began at Graft-areas of $50 \mathrm{~mm}^{2}, 30$ $\mathrm{mm}^{2}$, and $10 \mathrm{~mm}^{2}$ with properties of $100 \mathrm{MPa}, 300 \mathrm{MPa}$, and $10000 \mathrm{MPa}$, respectively (Table 3). The interspinous motion 
decreased as the Graft-area increased (Table 3, Fig. 4). The interspinous motion was less than $2 \mathrm{~mm}$ when the Graft-area was $190 \mathrm{~mm}^{2}$ with $100 \mathrm{MPa}$ cancellous bone, $140 \mathrm{~mm}^{2}$ with

Table 2. Characteristics of commercially available interbody cages

\begin{tabular}{|c|c|c|c|c|}
\hline & \multirow{2}{*}{$\begin{array}{c}\text { Size of cage } \\
\text { (depth } \times \text { width, } \mathrm{mm} \text { ) }\end{array}$} & \multicolumn{3}{|c|}{ Area of contact surface $\left(\mathrm{mm}^{2}\right)^{*}$} \\
\hline & & PEEK & Inside & PEEK+Inside \\
\hline \multirow[t]{2}{*}{$\mathrm{MC}+{ }^{\circledR}$} & $12 \times 14$ & 80.94 & 60.92 & 141.86 \\
\hline & $14 \times 17$ & 110.69 & 92.27 & 202.96 \\
\hline \multirow[t]{2}{*}{ Solis $^{\text {TM }}$} & $12 \times 14$ & 62.31 & 73.14 & 135.45 \\
\hline & $14 \times 16$ & 75.11 & 108.07 & 183.18 \\
\hline \multirow[t]{2}{*}{$\mathrm{C7}$} & $12 \times 14$ & 112.83 & 48.5 & 161.33 \\
\hline & $14 \times 16$ & 115.76 & 78.78 & 194.54 \\
\hline
\end{tabular}

Product information: MC+ ${ }^{\circledR}$ cage (LDR Medical, Troyes, France), Solis ${ }^{\text {TM }}$ cage (Stryker, Kalamazoo, MI, USA), and C7 cage (Medyssey, Jecheon, Korea). ${ }^{*}$ Contact area of polyetheretherketone (PEEK), the area inside the cage where the bone graft is filled in (Inside) and the sum of those areas (PEEK+Inside)

Table 3. Interspinous motion $(\mathrm{mm})$ between the flexion and extension finite element model according to the contact surface area of the interbody graft

\begin{tabular}{|c|c|c|c|}
\hline \multirow[t]{2}{*}{ Area $\left(\mathrm{mm}^{2}\right)$} & \multicolumn{3}{|c|}{$\begin{array}{l}\text { Young's modulus of the } \\
\text { incorporated interbody graft (MPa) }\end{array}$} \\
\hline & 100 & 300 & 10000 \\
\hline 10 & - & - & 17.54 \\
\hline 20 & - & - & 11.21 \\
\hline 30 & - & 15.04 & 6.55 \\
\hline 40 & - & 10.52 & 4.96 \\
\hline 50 & 13.21 & 7.74 & 3.80 \\
\hline 60 & 10.13 & 6.02 & 3.26 \\
\hline 70 & 8.16 & 4.90 & 2.85 \\
\hline 80 & 6.64 & 4.04 & 2.42 \\
\hline 90 & 5.54 & 3.48 & 2.16 \\
\hline 100 & 4.69 & 3.03 & 1.85 \\
\hline 110 & 4.04 & 2.67 & 1.56 \\
\hline 120 & 3.54 & 2.37 & 1.38 \\
\hline 130 & 3.15 & 2.14 & 1.25 \\
\hline 140 & 2.85 & 1.95 & 1.14 \\
\hline 150 & 2.60 & 1.79 & 1.03 \\
\hline 160 & 2.35 & 1.63 & 0.90 \\
\hline 170 & 2.14 & 1.48 & 0.79 \\
\hline 180 & 2.02 & 1.38 & 0.76 \\
\hline 190 & 1.82 & 1.20 & 0.62 \\
\hline 200 & 1.68 & 1.06 & 0.51 \\
\hline
\end{tabular}

$300 \mathrm{MPa}$ cancellous bone and $100 \mathrm{~mm}^{2}$ with $10000 \mathrm{MPa}$ cortical bone (Table 3, Fig. 4). Compared with the contact area of commercially available cages (Table 2), the minimal Graft-area was not obtainable in most cages with only the formation of InGBB, even if InGBB was achieved with the cortical bone $(10000 \mathrm{MPa})$. When the contact areas between the PEEK and vertebral endplate were considered together, the minimal Graft-area was obtainable with a large-sized cage, even when InGBB was formed with the property of cancellous bone (100 $\mathrm{MPa})$. However, the strength of the union between the PEEK and endplate was not assessable.

\section{Illustrative cases}

\section{Case 1}

A 71-year-old man with cervical myelopathy underwent C5-6 ACDF with a stand-alone MC $+{ }^{\circledR}$ cage (depth $\times$ width $=14$ $\times 17 \mathrm{~mm}$ ) filled with demineralized bone matrix (DBM). CT scans and plain radiographs obtained 3 months postoperatively demonstrated that neither InGBB nor ExGBB was formed. Interspinous motion was $2.27 \mathrm{~mm}$ (Fig. 5A). Equivalent images acquired 12 months postoperatively revealed that both InGBB and ExGBB were formed, but lucent lines were present in both InGBB and ExGBB (Fig. 5B). Interspinous motion was $2.34 \mathrm{~mm}$ (Fig. 5B). At 24 months postoperatively, the lucent line in InGBB was present, but the lucent line in ExGBB

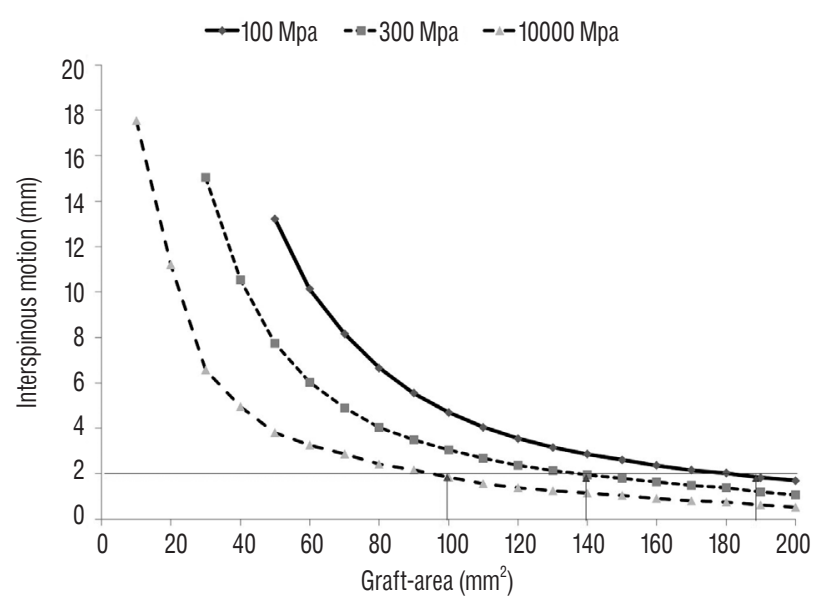

Fig. 4. Interspinous motion according to the interbody graft properties. The interspinous motion decreased as the contact area of the interbody graft (the Graft-area) increased. The interspinous motion was less than 2 $\mathrm{mm}$ when the area of the incorporated interbody graft was $190 \mathrm{~mm}^{2}, 140$ $\mathrm{mm}^{2}$, and $100 \mathrm{~mm}^{2}$ with properties of $100 \mathrm{MPa}$ and $300 \mathrm{MPa}$ cancellous bone and $10000 \mathrm{MPa}$ cortical bone, respectively. 

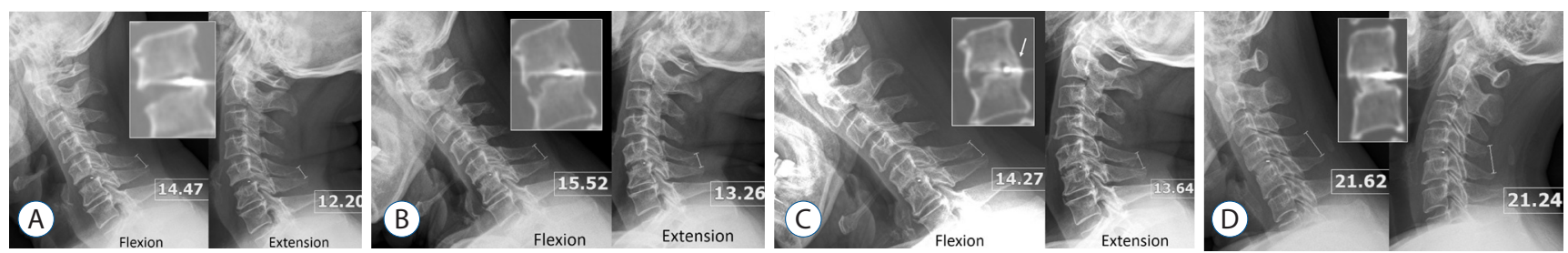

Fig. 5. Illustrative cases. A : Case 1. A 71-year-old man underwent C5-6 anterior cervical discectomy and fusion (ACDF) with a stand-alone MC+ ${ }^{\circledR}$ cage (depth $\times$ width $=14 \times 17 \mathrm{~mm}$ ) filled with demoralized bone matrix (DBM). Computed tomography (CT; middle inserted figure) scans and plain radiographs obtained 3 months postoperatively demonstrated that neither intragraft bony bridging (InGBB) nor extragraft bone bridging (ExGBB) formed. The interspinous motion was $2.27 \mathrm{~mm}$. The interspinous distances are indicated in the figure in units of $\mathrm{mm}$. All radiological measurements were performed in $150 \%$ magnified images. B : The same images were obtained 12 months postoperatively and showed both InGBB and ExGBB. ExGBB formed both anterior and posterior to the cage (middle inserted figure). There were lucent lines in InGBB and ExGBB, and the interspinous motion was $2.34 \mathrm{~mm}$. C: At 24 months postoperatively, ExGBB was formed both anterior and posterior to the cage (middle inserted figure), and the posterior ExGBB encroached the spinal canal (arrow). The lucent line in InGBB was present, but the lucent line in the posterior ExGBB disappeared. The interspinous motion was $0.63 \mathrm{~mm}$. D : Case 2. A 43-year-old woman underwent C4-5 ACDF using the same cage and DBM used in case 1. Twelve months postoperatively, CT scans and plain radiographs revealed the complete formation and remodeling of InGBB with the density of cortical bone without a lucent line. The interspinous motion was $0.38 \mathrm{~mm}$ without the formation of ExGBB.

disappeared (Fig. 5C). The interspinous motion was $0.63 \mathrm{~mm}$ (Fig. 5C). ExGBB was formed posterior to the cage but encroached the spinal canal (Fig. 5C, arrow).

\section{Case 2}

A 43-year-old woman underwent C4-5 anterior cervical discectomy and fusion with the same cage and DBM as that used in case 1. CT scans and plain radiographs obtained 12 months postoperatively demonstrated that InGBB was completely formed with the density of cortical bone without a lucent line. Interspinous motion was $0.38 \mathrm{~mm}$ (Fig. 5D). The ExGBB was not observed. All radiological measurements were performed in $150 \%$ magnified images.

\section{DISCUSSION}

The objective of the present study was to determine, using FEA, the minimal area of contact surface of an interbody graft required to achieve solid bony fusion. The minimal Graft-areas for solid fusion were $190 \mathrm{~mm}^{2}, 140 \mathrm{~mm}^{2}$, and $100 \mathrm{~mm}^{2}$ with graft properties of 100, 300, and $10000 \mathrm{MPa}$, respectively. When the minimal Graft-areas were compared with those of commercially available cages, the InGBB was mostly insufficient for solid bony fusion, even if InGBB was achieved with a strong cortical bone. The contact strength between the cage and vertebral endplate may be less than those of InGBB. This result implies that the formation of ExGBB may be inevitable after ACDF with a stand-alone cage. Various factors such as biological aspects of patients, including age and comorbidities and graft material (autologous bone graft) are related to ExG$\mathrm{BB}$, but an inadequate area or strength of InGBB might be one causative factor for ExGBB.

\section{ExGBB}

Song et al. ${ }^{22)}$ assessed anterior cervical fusion using CT scans in 254 surgically confirmed cases and suggested that ExGBB was more reliable than InGBB for detecting and assessing cervical fusion. The sensitivity, specificity, positive predictive values and negative predictive values of ExGBB to determine solid bony union were $100 \%, 86.5 \%, 70.8 \%$, and $100 \%$, respectively, whereas those of InGBB were $78.8 \%$, $53.2 \%, 35.5 \%$, and $88.5 \%$, respectively, after the use of a standalone cage for $\mathrm{ACDF}^{22}$. This result implies that InGBB is not sufficient for solid fusion and that ExGBB may be necessary for solid bony fusion in most patients ${ }^{22}$. ExGBB may form sequentially or simultaneously with InGBB during the solid fusion process, and we hypothesized that ExGBB may form to provide the strength required for solid fusion in some patients ${ }^{1,19,22)}$. The formation of ExGBB strengthens the fusion mass; however, it is impossible to control whether ExGBB forms anterior or posterior to an interbody graft ${ }^{15)}$. ExGBB encroached the spinal canal in 21/27 (78\%) patients after ACDF with a stand-alone cage and 6/31 (19\%) patients after ACDF with an autologous iliac bone and plate fixation ${ }^{15)}$. Although the clinical significance of ExGBB has not been reported, solid bony union without the formation of ExGBB to- 
ward the spinal canal may be an ideal condition ${ }^{15)}$.

\section{The properties of InGBB}

The present study demonstrated that less Graft-area was required for cortical bone than for cancellous bone. In the two illustrated cases, the same cage $\left(\mathrm{MC}+{ }^{\circledR}\right.$ cage, depth $\times$ width $=14$ $\times 17 \mathrm{~mm}$, inside area $92.27 \mathrm{~mm}^{2}$ ) and bone substitute were used. However, the first case (Fig. 5A-C) exhibited delayed fusion 24 months postoperatively with the formation of ExGBB. Because the properties of InGBB with a lucent line were lower than those of cortical bone, the necessary Graft-area might be greater than $100 \mathrm{~mm}^{2}$, and the formation of ExGBB was inevitable.

The second case was a typical example of successful solid fusion after ACDF. Fusion was achieved within 12 months. CT scans revealed the complete formation and remodeling of InGBB with cortical bone without the formation of ExGBB (Fig. 5D). Although there was a difference between the Graftarea $\left(100 \mathrm{~mm}^{2}\right.$ with $10000 \mathrm{MPa}$ cortical bone) and inside area $\left(92.75 \mathrm{~mm}^{2}\right)$ of the cage, the area and property of InGBB in the second case appeared to be sufficient for solid fusion. Although the surgical level was the same, the following biological characteristics of the two patients were not equal : age and gender. Old age might delayed the fusion process and result in the formation of InGBB with weak bone quality. Therefore, the Graft-area with lower property of InGBB might not be sufficient, and ExGBB was formed. These two cases demonstrate that both Graft-area and InGBB properties influence the formation of ExGBB.

\section{Suggestions for future innovation}

Cervical interbody cages have evolved based on clinical outcomes, fusion rates, the incidence of subsidence and complications ${ }^{2}$. However, the issue of ExGBB has not been addressed in this evolution. Although the designs of the example cages analyzed in the present study are similar to those of mainstream cages, the areas inside the commercial cages are smaller than the minimal Graft-area for solid fusion with only InGBB. Although the biomechanical effect of the cagevertebral endplate was not assessable, it seemed that the Graft-area was insufficient for solid bony union even when the area of PEEK was considered, potentially leading to the formation of ExGBB.

Increasing the area inside the cage to increase the contact area of InGBB may be a solution, but decreased cage stiffness should be considered. If the area of InGBB cannot be increased with current designs, osteointegration of the cage itself into the vertebra through the bioactivation of surface materials or expansion of the contact area of the cage may increase areas of fusion mass and reduce the requirement for $\mathrm{ExGBB}^{2)}$. With the currently available cages, the application of a plate/screw system might reduce the formation of $\mathrm{ExGBB}^{15}$.

\section{Limitations of the study}

This study has several limitations. First, solid bony union with complete remodeling of bone graft was not always a necessary condition for successful clinical and radiological outcomes. Because of various factors such as supporting muscles, ligaments, and the biomechanical effect between the cage-vertebral endplate and ExGBB, successful outcomes have been reported after ACDF with a stand-alone cage ${ }^{19,22)}$. In the present study, we used the liberal criterion of $2 \mathrm{~mm}^{11)}$ based on the above-mentioned factors. However, the cut-off for successful clinical and radiological outcomes in practice may differ from that in the present study, as shown in case 2. A postoperative radiological analysis is required to define the exact Graft-area for solid fusion.

Second, InGBB and ExGBB may be formed simultaneously during the fusion process. Therefore, ExGBB may be formed even in the presence of adequate InGBB contact area because of the insufficient strength of InGBB until the remodeling of InGBB is complete (Figs. 4 and 5). However, we could not simulate such scenarios with the current FEA.

Third, the clinical significance of ExGBB was not addressed. The formation of ExGBB might be the process toward a successful arthrodesis. Moreover, the influences of the biological factors of patients and graft materials were not considered in FEA. Therefore, the hypothesis of the present study and suggestions for future innovation may be appropriate only after confirmation of the clinical significance of ExGBB ${ }^{15)}$. The present result was obtained from FEA, and these limitations of FEA must be considered when interpreting the present results. Nonetheless, solid fusion with the formation of ExGBB may be an unpredictable radiological outcome. The present study may prove beneficial for highlighting the issue of ExG$\mathrm{BB}$ and suggesting one causative factor for the formation of ExGBB with suggestions for refinement. 


\section{CONCLUSION}

ExGBB may be formed to compensate for insufficient InG$\mathrm{BB}$. Although various factors may be involved, solid fusion with less formation of ExGBB may be achieved with refinements in biomaterials, such as the use of osteoinductive cage materials; changes in cage design, such as increasing the area of PEEK or the inside cage area for bone grafts; or surgical techniques, such as the use of plate/screw systems.

\section{- Acknowledgements}

CKC : This work was supported by a National Research Foundation of Korea (NRF) grant funded by the Korean government (MSIP) (No. 2010-0028631). CHK : This work was supported by Grant No. 0320160210 (2016-1062) from Seoul National University Hospital. The authors declare no conflict of interest concerning the materials or methods used in this study or the findings described in this paper. This study was approved by the institutional review board (No. 1512-126-729 and 1607-003-771).

\section{References}

1. Buchowski JM, Liu G, Bunmaprasert T, Rose PS, Riew KD : Anterior cervical fusion assessment: surgical exploration versus radiographic evaluation. Spine (Phila Pa 1976) 33 : 1185-1191, 2008

2. Chong E, Pelletier MH, Mobbs RJ, Walsh WR : The design evolution of interbody cages in anterior cervical discectomy and fusion: a systematic review. BMC Musculoskelet Disord 16 : 99, 2015

3. Faizan A, Goel VK, Garfin SR, Bono CM, Serhan H, Biyani A, et al. : Do design variations in the artificial disc influence cervical spine biomechanics? A finite element investigation. Eur Spine J 21 Suppl 5 : S653S662, 2012

4. Floyd T, Ohnmeiss $D$ : A meta-analysis of autograft versus allograft in anterior cervical fusion. Eur Spine J 9 : 398-403, 2000

5. Galbusera F, Bellini CM, Costa F, Assietti R, Fornari M : Anterior cervical fusion: a biomechanical comparison of 4 techniques. Laboratory investigation. J Neurosurg Spine 9 : 444-449, 2008

6. Galbusera F, Bellini CM, Raimondi MT, Fornari M, Assietti R : Cervical spine biomechanics following implantation of a disc prosthesis. Med Eng Phys 30 : 1127-1133, 2008

7. Ha SK : Finite element modeling of multi-level cervical spinal segments (C3-C6) and biomechanical analysis of an elastomer-type prosthetic disc. Med Eng Phys 28 : 534-541, 2006

8. Harrison DE, Harrison DD, Cailliet R, Troyanovich SJ, Janik TJ, Holland B : Cobb method or harrison posterior tangent method: which to choose for lateral cervical radiographic analysis. Spine (Phila Pa 1976) 25 : 2072-2078, 2000

9. Heneghan HM, McCabe JP : Use of autologous bone graft in anterior cervical decompression: morbidity \& quality of life analysis. BMC Musculoskelet Disord 10 : 158, 2009

10. Jung TG, Woo SH, Park KM, Jang JW, Han DW, Lee SJ : Biomechanical behavior of two different cervical total disc replacement designs in relation of concavity of articular surfaces: ProDisc $-C^{\circledR}$ vs. Prestige-LP ${ }^{\circledR}$. Int J Precis Eng Manuf $14: 819-824,2013$

11. Kaiser MG, Mummaneni PV, Matz PG, Anderson PA, Groff MW, Heary RF, et al. : Radiographic assessment of cervical subaxial fusion. J Neurosurg Spine $11: 221-227,2009$

12. Kim CH, Chung CK, Choi Y, Hwang ST, Kim SM, Park SB : The patientreported outcome of chronic pain after the harvest of anterior iliac bone for anterior cervical arthrodesis. J Clin Neurosci 36 : 102-107, 2017

13. Kim CH, Chung $\mathrm{CK}$, Hahn $\mathrm{S}$ : Autologous iliac bone graft with anterior plating is advantageous over the stand-alone cage for segmental lordosis in single-level cervical disc disease. Neurosurgery $72: 257-265$ discussion 266, 2013

14. Kim CH, Chung CK, Jahng TA, Park SB, Sohn S, Lee S : Segmental kyphosis after cervical interbody fusion with stand-alone polyetheretherketone (PEEK) cages: a comparative study on 2 different PEEK cages. J Spinal Disord Tech 28 : E17-E24, 2015

15. Lee $\mathrm{SE}$, Chung $\mathrm{CK}, \mathrm{Kim} \mathrm{CH}$ : Difference in canal encroachment by the fusion mass between anterior cervical discectomy and fusion with bone autograft and anterior plating, and stand-alone cage. J Clin Neurosci 29 : 121-127, 2016

16. Mackiewicz A, Banach M, Denisiewicz A, Bedzinski R : Comparative studies of cervical spine anterior stabilization systems - finite element analysis. Clin Biomech (Bristol, Avon) 32 : 72-79, 2016

17. Panjabi MM, Crisco JJ, Vasavada A, Oda T, Cholewicki J, Nibu K, et al. Mechanical properties of the human cervical spine as shown by threedimensional load-displacement curves. Spine (Phila Pa 1976) 26 : 2692-2700, 2001

18. Pechlivanis I, Thuring T, Brenke C, Seiz M, Thome C, Barth M, et al. : Non-fusion rates in anterior cervical discectomy and implantation of empty polyetheretherketone cages. Spine (Phila Pa 1976) 36 : 15-20, 2011

19. Rhee JM, Chapman JR, Norvell DC, Smith J, Sherry NA, Riew KD : Radiological determination of postoperative cervical fusion: a systematic review. Spine (Phila Pa 1976) 40 : 974-991, 2015

20. Shriver MF, Lewis DJ, Kshettry VR, Rosenbaum BP, Benzel EC, Mroz TE : Pseudoarthrosis rates in anterior cervical discectomy and fusion: a metaanalysis. Spine J 15 : 2016-2027, 2015

21. Song J, Taghavi CE, Hsu DW, Song KJ, Song JH, Lee KB : Radiological changes in anterior cervical discectomy and fusion with cage and plate construct: the significance of the anterior spur formation sign. Spine (Phila Pa 1976) 37 : 272-279, 2012

22. Song KS, Chaiwat P, Kim HJ, Mesfin A, Park SM, Riew KD : Anterior cervical fusion assessment using reconstructed computed tomographic scans: surgical confirmation of 254 segments. Spine (Phila Pa 1976) 
Extragraft Bone Bridging | Kwon SW, et al.

$38:$ 2171-2177, 2013

23. Song KS, Piyaskulkaew C, Chuntarapas T, Buchowski JM, Kim HJ, Park MS, et al. : Dynamic radiographic criteria for detecting pseudarthrosis following anterior cervical arthrodesis. J Bone Joint Surg Am 96 : 557-563, 2014

24. Yoganandan N, Kumaresan S, Pintar FA : Geometric and mechanical properties of human cervical spine ligaments. J Biomech Eng 122 : 623-629, 2000

25. Zhang QH, Teo EC, Ng HW, Lee VS : Finite element analysis of momentrotation relationships for human cervical spine. J Biomech 39 : 189193, 2006 